\title{
Developing Virtual Class Room Models with Bio Inspired Algorithms for E-Learning: A Survey for Higher Technical Education for Saudi Arabia Vision 2030
}

\author{
Khalid A. Fakeeh, PhD \\ King Abdullaziz University Jeddah, \\ Saudi Arabia
}

\begin{abstract}
In recent times there has been a growing trend for more information and knowledge to enhance learning based on cognitive load theory with increased use of Educational Technology based on Web ICT with online education resources. There are also various instructional and expert models being developed for the adaptive e-learning mechanisms as required for effective learning based on Genetic, Neural Networks, Swarm Intelligence and other Bio inspired algorithms or Evolutionary algorithms. Computational Intelligence or Artificial Intelligence has also established new paradigms for Learning Systems in creating virtual class rooms in the physical absence of tutors. It is also possible to create virtual labs on which students that are registered can carry out their experiments from remote with Interactive Intelligent Tutoring Systems.
\end{abstract}

The current paper will develop a problem model using Markov Chain and greedy algorithms for Tutor or Instructor -Student interactive model for virtual labs and virtual class rooms which will be built on the Deep Belief Network architecture as a novel approach for state-of-art courses related to Energy and Wireless Communication for Higher Education proposed as part of Inter University Research Groups. Further, a Bio inspired Differential Evolution algorithm will be deployed for the virtual labs and virtual class rooms to meet the specific learning requirements for the Instructor-Student interactions specific to this E-learning platform.

The proposed study will help improve the learning environment to stimulate creativity and innovation as envisaged by the Ministry of Education under the Saudi Arabia Vision 2030 and will help in moving towards creating an international benchmark for deploying innovative E-learning mechanisms for Higher Education.

\section{Keywords}

Interactive Intelligent Tutoring Systems, Greedy Algoirthm, Markov Chain, Differential Evolution, Deep Belief Network, Virtual Class Labs

\section{INTRODUCTION}

As Distance Learning is being implemented across various universities there has been a growing need to develop collaborative setup amongst universities to form groups for various teaching and research projects especially for the higher education related to science and technology to be able to meet the empirical demand for manpower across various sectors of the Industry and Research Institutes as part of the global trend. Elearning has also worked towards transforming several countries into vibrant knowledge economies increasing the human knowledge capital. There is also a growing focus to implement this for higher education in science and technology with focus towards state-of-the-art research for which various computational techniques are being evolved.

Several initiatives in this direction have already been taken up by Ministry of Education (MOE) in Kingdom of Saudi Arabia (KSA). A Knowledge International University (KIU) has been established, dedicated to the use of e-learning resources. Further, MOE to help universities adopt e-learning have created a repository of e-learning materials including e-books for medical, engineering, humanities and computer science courses for academics and training. The KSA universities have also implemented solutions for comprehensive learning management systems, virtual class rooms, collaboration tools, content authoring and capturing tools and digital repository systems. The lecture rooms are also equipped with interactive white boards, data shows, e-podiums, video conferencing solutions and multimedia centers, etc. These facilities have enabled students to prefer for E-learning courses especially in Computer Science. The growth of internet population in KSA has further increased interest to take up online courses to upgrade skills, take specialized courses for jobs and for higher degrees. However, for implementing E-learning for higher education has several challenges and the current technical obstacles are mostly related to insufficient technical skills in building and maintaining web based teaching materials, lack of computer laboratories in educational institutes, response and attitude towards solutions, scarcity of technicians and technical glitches with Test Management systems and lack of computer laboratories with several educational institutes are some of the issues faced by the teaching faculties. This is besides problems faced with the current networks and ICT infrastructures that are major impediments towards quality in e-learning. This creates a need to develop mechanisms to improve quality to motivate students taking up higher education in the area of science and technology. There is also a need to motivate faculty members to engage in distance education by demonstrating how effective E-learning methods are when deployed and implemented. Further, to be able to meet the current learning requirement towards the Saudi Arabia vision 2030 a collaborative effort needs to be taken by the universities in Saudi Arabia with various universities in USA, UK, European Union, South Asia and South East Asian countries along with China, Japan and South Korea under several joint projects in creating an interactive state of the art virtual class rooms and virtual labs to provide larger benefit to students taking up Higher Education with E-learning and also as mentioned in [7] will help in reducing expenditure of the Saudi Arabian Government for scholarships abroad which is currently focused on with water, energy, biotechnology, material and building and construction technology as a sector for creating its knowledge economy. The Section II in this paper will demonstrate some of the existing successful working models for a Virtual Class Room and Virtual labs along with the implementation of the bio 
inspired algorithms for these labs. Section III will develop deep belief networks for the virtual labs as universities collaborate for forming joint research groups resolving problem models identified with the Markov Models for the Virtual Class rooms.

\section{RELATED WORK}

With the National Development Programme as mentioned in [7] to improve learning environment and teaching methods by the Saudi Arabian Government, there is an aspiration to build an education system aligned with market needs and creating economic opportunities for the entrepreneur, the small enterprise as well as the large corporation. As per the reports in researchnester.com the e-learning market in Middle-East was expected to reach up to USD 558.3 million in 2016 from USD 379 million during the year 2011 and is likely to expand at a CAGR of $17.4 \%$ at the forecast period of 2016-23. Further, market segmentation of the E-learning has been done on the basis of Technology which includes- Rapid Online Learning, Learning Management System(LMS),Mobile e-learning, Podcasts ,Virtual Classroom, Application Simulation ,Knowledge Management system, Learning content Management System , Components which involves content, supporting services, faculty staff and end users which includes the Higher education, healthcare and corporate sectors. The region-wise market for E-learning has also been segmented on the basis of countries which includes UAE, Saudi Arabia, Qatar, Bahrain and Oman. Also, there is a major focus on achieving excellence with higher education within the universities in Saudi Arabia. The need for improving teaching methods for Higher Education as mentioned in [6] can be best achieved by using emerging technologies that are reshaping the landscape for higher education. The teachers and students can have access to MOOC (Massive Open Online Courses), Open Educational Resources (OER) and other online resources to reinforce the teaching-learning process common in many institutes of higher education as part of the technology segment of E-learning. We can use the parents-teacher model in [22] as defined by the author for monitoring progress of a learner's multi-instructional environment. Some of the virtual class room and lab models will be explored in this section under the adaptive e-learning mechanism with its brief background to analyse its impact in teaching and learning methods applicable for institutes of higher technology learning in Saudi Arabia. The section will also analyse virtual class rooms based on markov process chain and how met heuristic optimization approach using Bioinspired algorithms can be best used to create an adaptive virtual class room environment for improved learning experience. Further a setup to establish virtual labs is also being explored in this section.

\subsection{Virtual Class Room Models}

As part of the technology drive for e-learning with the virtual class rooms according to [5] a digital university has made following enhancements from being organizational specific to user centric to create learning management systems that are effective to create enhanced learning for the students (Refer Figure 1):

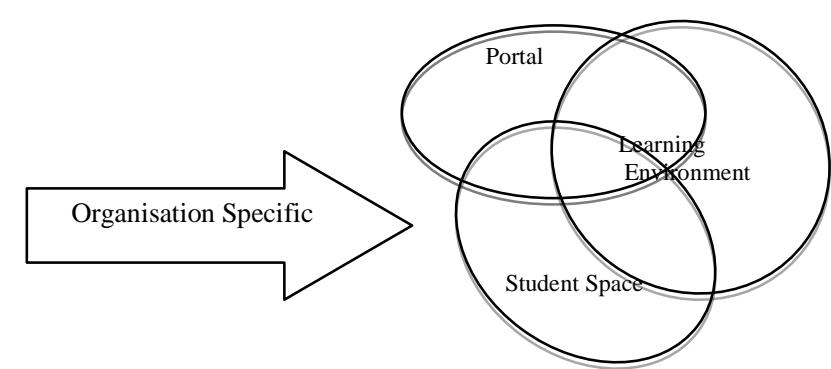

Figure 1(a): Organizational Specific Digital University [5]

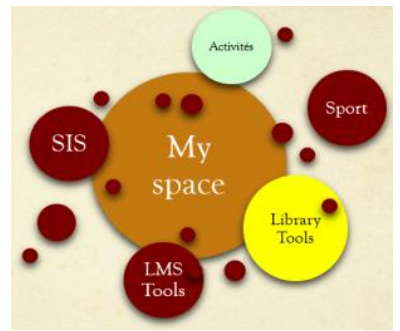

Figure 1(b): User Centric Approach for digital university [5]

The user centric approach creates learning analytics which includes measurement, collection, analysis and reporting of data about learners with contexts for purposes of understanding and optimizing learning and the environments in which it occurs. This has high potential impact to improve student's success or is an indicator of their progress. However, the limitations with these learning analytics tool includes lack of valid data from many systems, privacy of data and defining predictive indicators. A typical Intelligent Tutor System workflow for creating user centric approach for learning can be seen here in Figure 2.

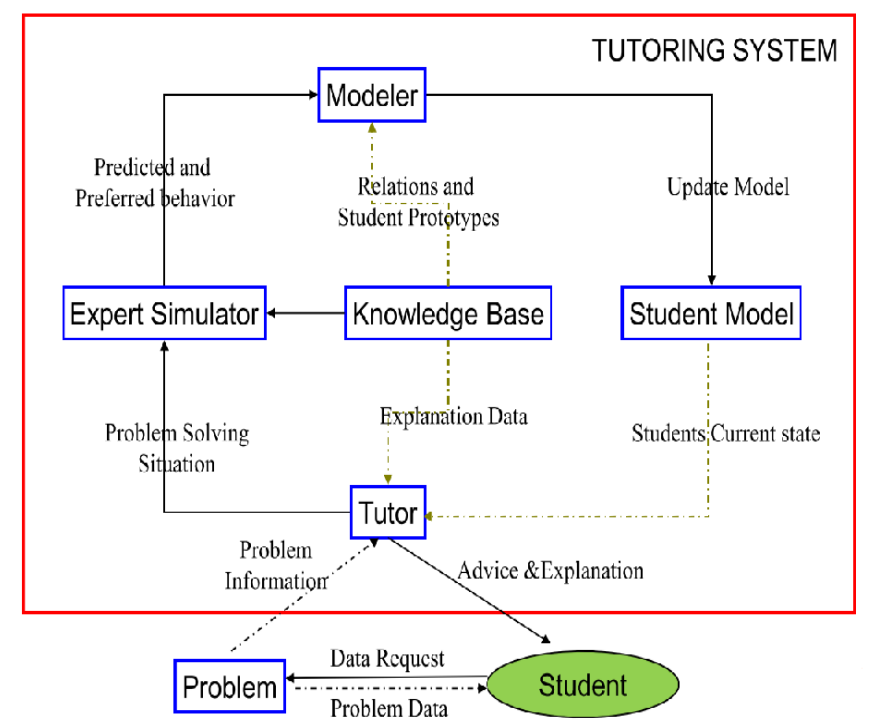

Figure 2: Intelligent Tutoring System for a virtual classroom [3]

An intelligent tutoring system includes traditionally a domain module which has knowledge database and determines the domain on which instructions are intended by this system. This is prepared based on the cognitive psychology of human skill acquisition which can be determined using Genetic Algorithm (the following section will give more insight to various Bio inspired algorithms for improving Instructor-Student interaction in a virtual classroom). It also includes a task module 
environment for student-teacher interaction and Pedagogical/Tutoring module which is derived from the present state of the domain module and multilevel instruction structure can be built as can be referred from [3] and is shown in Figure 3 here as follows:

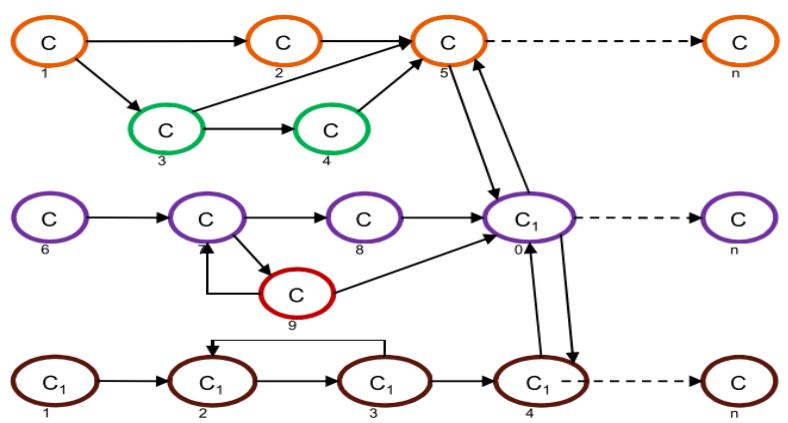

Figure 3: A Multilevel Instruction structure with $C_{n}$ stage of domain knowledge in the $n^{\text {th }}$ stage [3]

A student module records the students' knowledge state which is further analysed by the domain module. The inter-relation of these components determines developing an adaptive tutor module with the operational flow explained in Figure 2.

Further, to this an Intelligent Adaptive learning can be deployed as an educational method with computers as interactive teaching device, to orchestrate the allocation of human and mediated resources according to the unique needs of each learner. Computers adapt the presentation of educational material according to students' learning needs, as indicated by their responses to questions, tasks and experiences as can be seen in Figure 4.

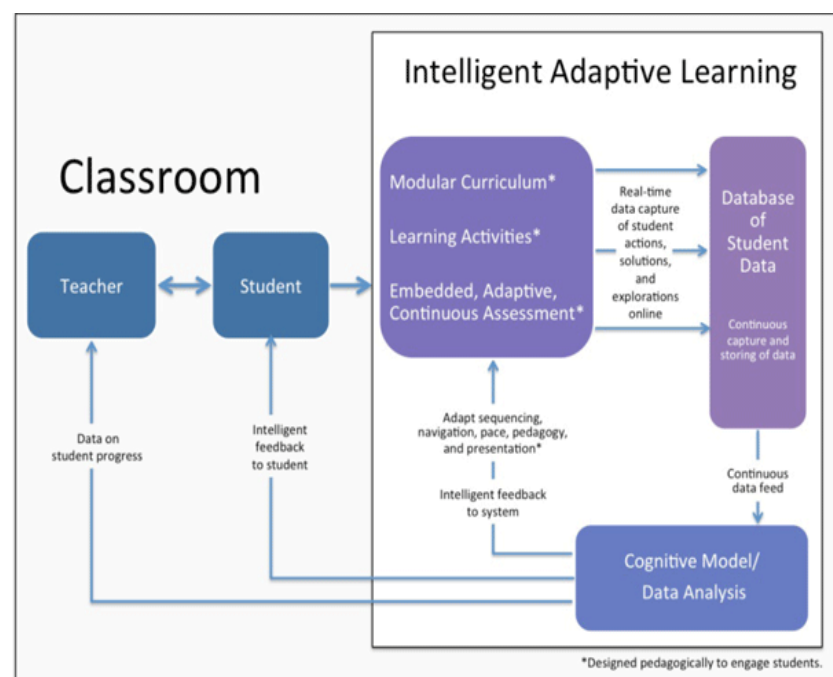

Figure 4: Intelligent Adaptive Learning Engine (Source: Dream Box)

Adaptive learning allows to best adapt learning to the capacities and feelings of each person. Learning analytics here is the method to introduce mentoring at an individual level during the time of mass education in a virtual classroom for optimized learning and regulating the cognitive load of the students by measuring the knowledge state and mental state of the learners with bio analysis signals as proposed in [3][10] including facial expressions, signals from brain using EEG, Electro-dermal signals, etc. Such methodologies can best be deployed to enhance
Instruction modules of Robot Tutors for a virtual class room setup.

In addition, E-learning environment is also trying to create flexibilities for learners by dynamically allocating resources in a Cloud Computing setup for a virtual class room. At [9] a scenario for Computer Science course has been discussed using the various layers of the Cloud Computing architecture which is highly dependent on a high bandwidth network for live video streaming in a virtual class room scenario. Figure 5 shows the identified courses of Computer Science integrated on a Cloud Computing Virtual Class Room network to focus on its teaching process.

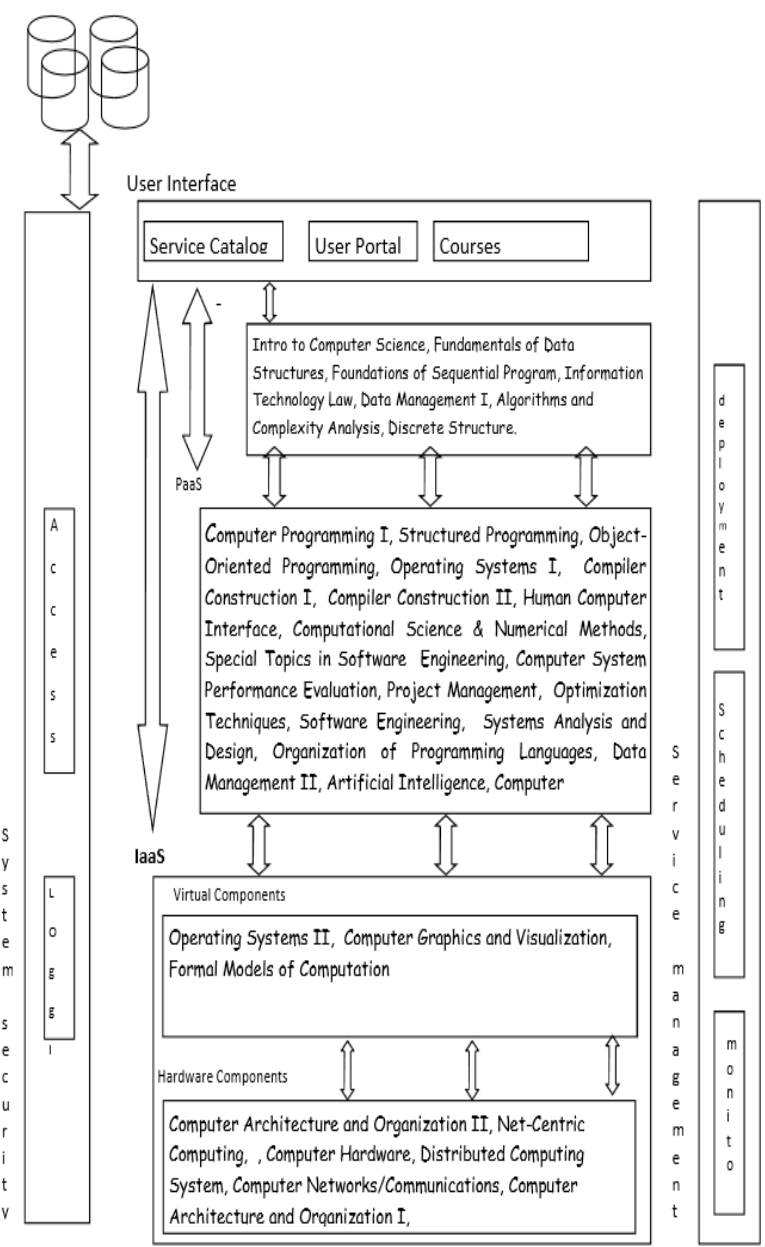

Figure 5: A Virtual Class Room Model on Cloud Computing [9]

It can be seen that the Virtual Class Room for Computer Science is deployed on the cloud computing frame work containing four layers namely the User Interface which is a learning management system providing interface to course repository, access to web application and service catalog related to the courses and other additional information at different layers of this framework. The SaaS layer provides access to courses for beginner's level, PaaS layer here incorporates the Human-Computer interaction course, that is needed especially for a platform or virtual machines to deploy and host the developed application for measuring and testing the usability of deployed system and includes courses related to Security solutions, Computer Networking as illustrated in Figure 5. The IaaS layer gives flexibility for Computer hardware, Parallel Computing and net-centric courses and virtualization can be done can be done with the Hardware 
courses while dealing with Hardware abstract layer here along with the Artificial Intelligence and machine learning tools. The Learning management system (LMS) here also has deployed three modules which includes User log database, system security, and service management. From [11] some of the most popular Learning Managements systems (LMS) for virtual class rooms are highlighted in Table I:

\begin{tabular}{|c|c|c|}
\hline S.No. & LMS & Key Features \\
\hline 1. & $\begin{array}{l}\text { Adobe } \quad \text { Captivate } \\
\text { Prime }^{*}\end{array}$ & $\begin{array}{l}\text { Includes functional features } \\
\text { like fluidic player, online } \\
\text { offline and mobile support } \\
\text { with learning at all the time. } \\
\text { Smart Enroller enable E- } \\
\text { Learning professionals to } \\
\text { quickly and effectively assign } \\
\text { roles and activities. Content } \\
\text { organization into modules, } \\
\text { courses or even whole } \\
\text { curricula is based on inbuilt } \\
\text { Learning Content } \\
\text { Management System (LCMS) } \\
\text { functionality. }\end{array}$ \\
\hline 2. & Docebo $L M S^{*}$ & $\begin{array}{l}\text { A SaaS based e-learning } \\
\text { system. This includes } \\
\text { gamification of learning } \\
\text { engagement. Integration } \\
\text { possible with third party web- } \\
\text { conferencing tool. }\end{array}$ \\
\hline 3. & Talent $L M S^{*}$ & $\begin{array}{l}\text { Can be accessed from any } \\
\text { mobile device including iPad, } \\
\text { iPhone and Android. It is } \\
\text { easy to integrate already } \\
\text { owned material into the LMS. } \\
\text { Support for the latest industry } \\
\text { standards, namely SCORM } \\
\text { (Sharable Content Object } \\
\text { Reference Model) \& Tin Can } \\
\text { [12]. }\end{array}$ \\
\hline 4. & The Academy LMS & $\begin{array}{l}\text { A gamified and engaging } \\
\text { social learning management } \\
\text { system. The responsive } \\
\text { interface allows easy access } \\
\text { from any device for intuitive } \\
\text { learner dashboard. }\end{array}$ \\
\hline 5. & ExpertusONE & $\begin{array}{l}\text { Its offers offline sync for } \\
\text { SCORM content with mobile } \\
\text { friendly interface with in- } \\
\text { built virtual conferencing } \\
\text { tool. }\end{array}$ \\
\hline 6. & Moodle & $\begin{array}{l}\text { It features learner tracking, } \\
\text { support for multimedia, } \\
\text { information dashboard with } \\
\text { the support and ability to } \\
\text { create on-line courses that are } \\
\text { mobile-friendly and integrate } \\
\text { third party add-ons. }\end{array}$ \\
\hline 7. & ATutor & $\begin{array}{l}\text { It includes features that are } \\
\text { useful ranging from email } \\
\text { notifications to file storage, e- } \\
\text { learning assessment tools, } \\
\text { analytics, file backups and }\end{array}$ \\
\hline
\end{tabular}

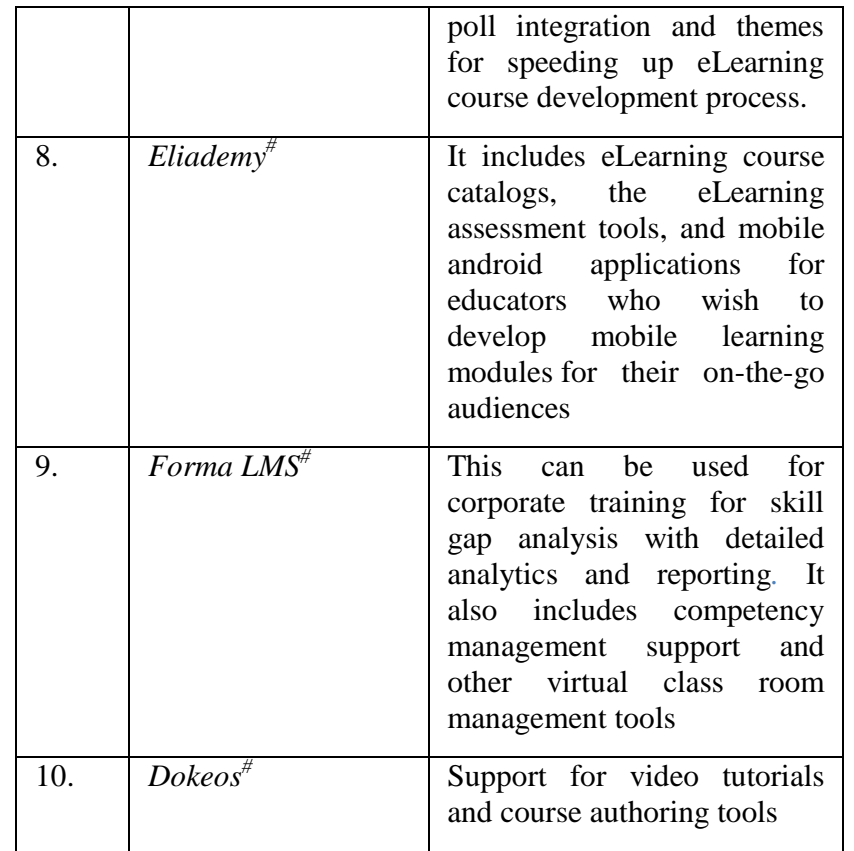

*Top 5 Cloud based Learning Management Systems [11] \#Top 5 Open Source Learning Management Systems [11]

\subsection{The Bio Inspired Algorithms for Virtual Class Room Models}

An E-learning system for a virtual class room is an intelligent adaptive system based on the human to machine, machine to human, human to human and machine to machine interaction. Further in [1] it mentions that the components of an E-learning system including the expert model, learner model, instructional model and interface model adapt according to the different learning sides of the learners where systems use learning styles to guide the design of the educational contents preferred by the individuals or guide the adaptation of the structure of the contents based on the mental process of the individual which includes particular style for thinking, remembering or perception for the contents. This classification with learners requires creating different set of rules for an instructional situation or pedagogical tasks for different unpredictable scenarios making it a very complex system for an adaptive e-learning environment in a virtual classroom. To be able to create an optimal e-learning environment and resolving issues related to its flexibility there is a need to adapt new computing techniques based on the bio inspired algorithms. Several studies are recently being carried out in the field of evolutionary computing or biocomputing to improvise the existing algorithms according to a vast variety of problems in an e-learning environment. In [1] different virtual classroom models have been created based on the two bio inspired techniques namely neural networks and swarm intelligence techniques for an adaptable e-learning system. In [13] a hybrid algorithm using CSO (Cat Swarm Optimization) with PSO (Particle Swarm Optimization) and GA (Genetic Algorithm) for emotion recognition (ER) has been explained demonstrating its effectiveness for E-learning systems using the following framework in Figure 6: 


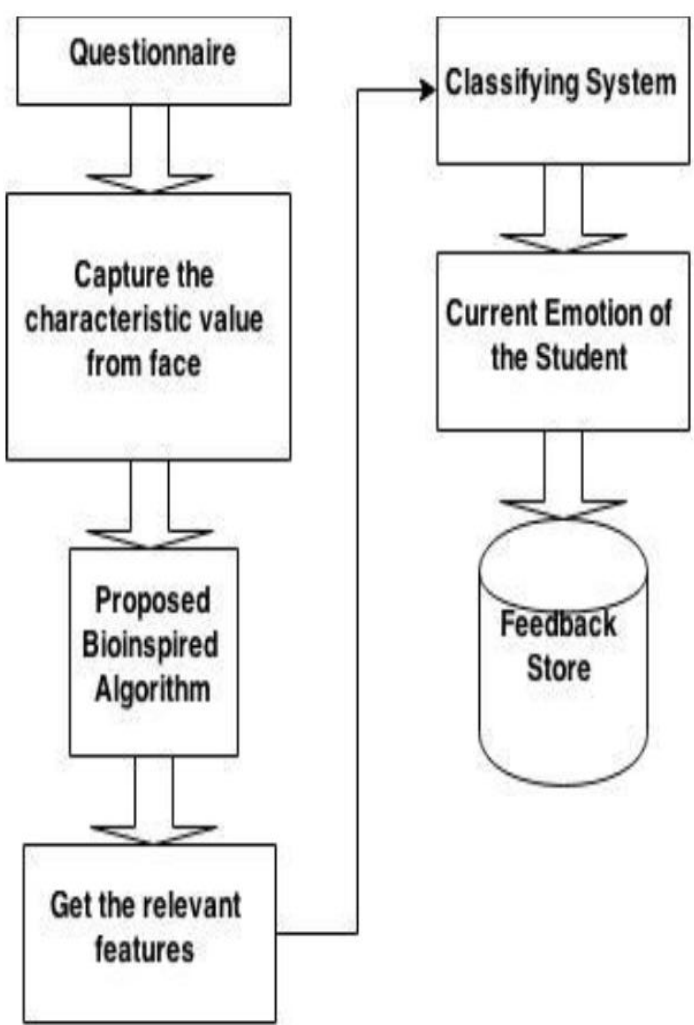

Figure 6: Elearning process using the Hybrid Bioinspired Algorithm for Emotional Recognition[13]

Here 6 basic emotions of students were extracted based on the following framework for the Emotional Recognition System as shown in Figure 7 and explained in the Hybrid Bio inspired algorithm.

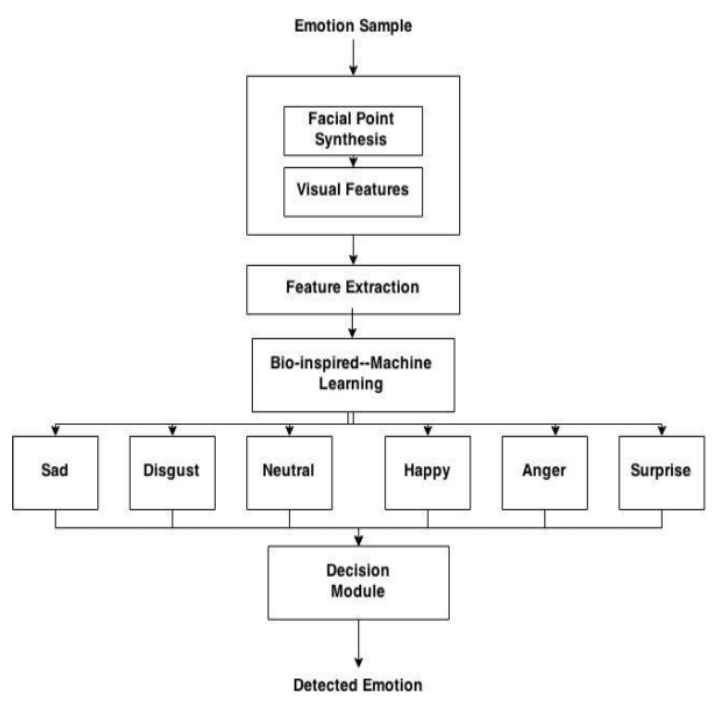

Figure 7: The framework for the Emotional Recognition System [13]

Here, CSO algorithm is a modification of the Swarm Intelligence algorithm. In [1] Swarm Intelligence is defined as the collective behavior of decentralized and self-organized systems. It is composed of a population consisting of simple agents that interact locally with one another and with the environment by following simple rules. The agents' behavior is defined by a certain degree of randomness and their social interactions are inspired by nature. Swarm Intelligence techniques are based on applying behavioral response to the environmental state, which serves as a work state memory and do not depend on specific agents. The six basic emotions are classified in the algorithm at [13] as follows:

\section{Algorithm I: Hybrid Algorithm using CSO-GA-PSO- SVM}

Input: Training feature set [each feature vector contains 79 facial features]

Output: Feature vector indices [It will list out the indices of feature vector which provide best accuracy]

1. Randomly initialize cat's position and speed

2. For each cats until required accuracy is obtained or termination requirement satisfied

3. Check whether to choose cat's current characteristic set

4. Derive characteristic subsets for cats

5. Compute SVM fitness value for subsets found in Step 4

6. Execute Modified CSO algorithm

7. end

8. Optimal characteristic subset

The location of each particle is determined by vector $\mathrm{xi}=(\mathrm{xi} 1$, xi2, xi3 ... xin) taking each bit xij (with $\mathrm{j}$ in $\{1, \mathrm{~N}\}$ binary values 0 or1. For our problem this xij represents the feature and whole vector is the feature set. The algorithm developed here uses the Cat's behavior. Cats are observant and their behavior is captured via Seeking Mode (which includes resting and observing). The Genetic Algorithm (GA) operator "Mutation" (the others include Selection, crossover based on fitness function criteria) is used for new divergence in the next iteration. Here the SVM (Supported vector machine) classifier works in conjunction with the algorithm as a fitness function for 15 relevant features giving best accuracy. The convergence in the Hybrid algorithm is best achieved by using the combination of PSO and GA used in Tracing mode (which includes moving towards target by the cat). The particle movement is defined by the $\mathrm{Eq}(1)$ as follows:

$$
X^{k}(t+1)=\left(P^{k}(t)-X^{k}(t)\right)+\left[X^{t}(t)\right]^{\prime}
$$

The subtraction operator represents the crossover operation between two individuals. $\left[X^{t}(t)\right]^{\prime} \quad$ represent random mutation operation on $X^{k}(t)$, and the addition represents selection operation from the

Individuals. Here, $P^{k}(t)$ represent position of global best particle. The process flow for the Modified CSO algorithm can be referred from Figure 8 as follows: 


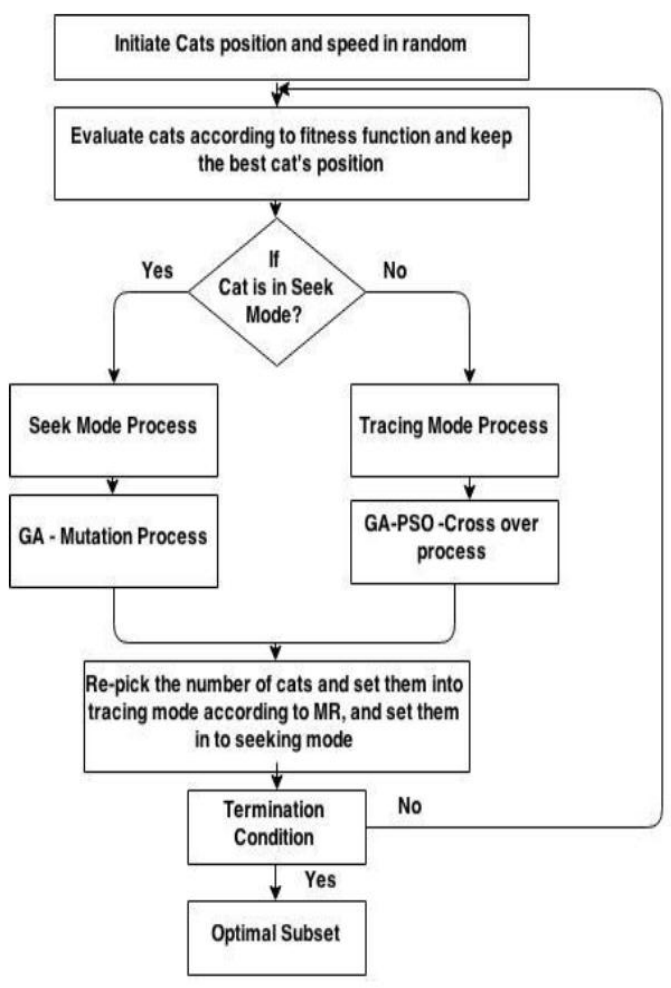

Figure 8: Modified CSO algorithm for Emotional Recognition

This system is based on NP-Hard problem and enables as a feedback on student's performance and improvements to be introduced in a Virtual Class room teaching-learning process. In [1] a case study has been done for an Electronic Course using following methods:

\subsection{Developing a Conceptual Map}

Here, the Electronic Course is modelled based on a Conceptual map [14]

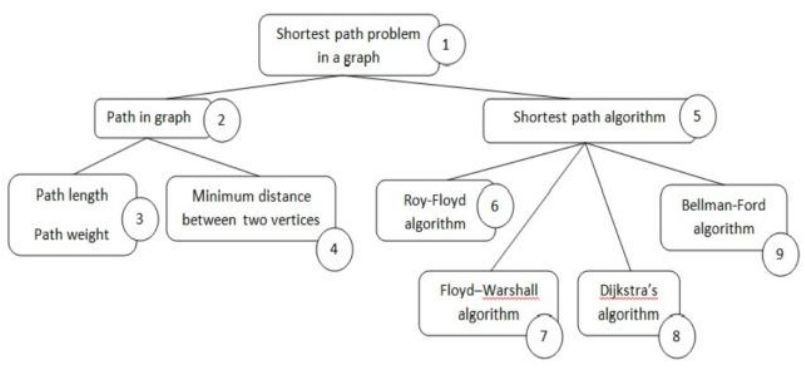

Figure 9: An Electronic Course on a Conceptual Map [1]

Each node $i$ the number of pedagogical resource is $\boldsymbol{n} \boldsymbol{L} \boldsymbol{U}_{\boldsymbol{i}}$ or student can be associated with a Learning Unit. $\boldsymbol{L} \boldsymbol{U}$. The maxim number of combination is $\Pi_{i=1}{ }^{K} \mathrm{nLU}_{\mathrm{i}}$, so the teaching models is less than $\boldsymbol{\Pi}_{i=l}{ }^{\boldsymbol{K}} \boldsymbol{n} \boldsymbol{L} \boldsymbol{U}_{\boldsymbol{i}}$. A Learning Unit (LU) is included in pedagogical or instructor's model. So learner or a node can be taught different learning units as can also be seen for the Electronic course in Figure 9. To be able resolve the association between the learner and learner unit we may refer to the bio inspired computing algorithm at [1]. i. Using the Swarm Intelligence technique with Artificial Bee Colony Algorithm between the Learner and the Learning Unit

A general schema from [1] can be referred for the operational function of the Artificial Bee Colony algorithm or $\mathrm{ABC}$ algorithms for optimization problem as the position of the food source based on the model proposed by Stanarevic \& Bacanin, 2011 as follows:

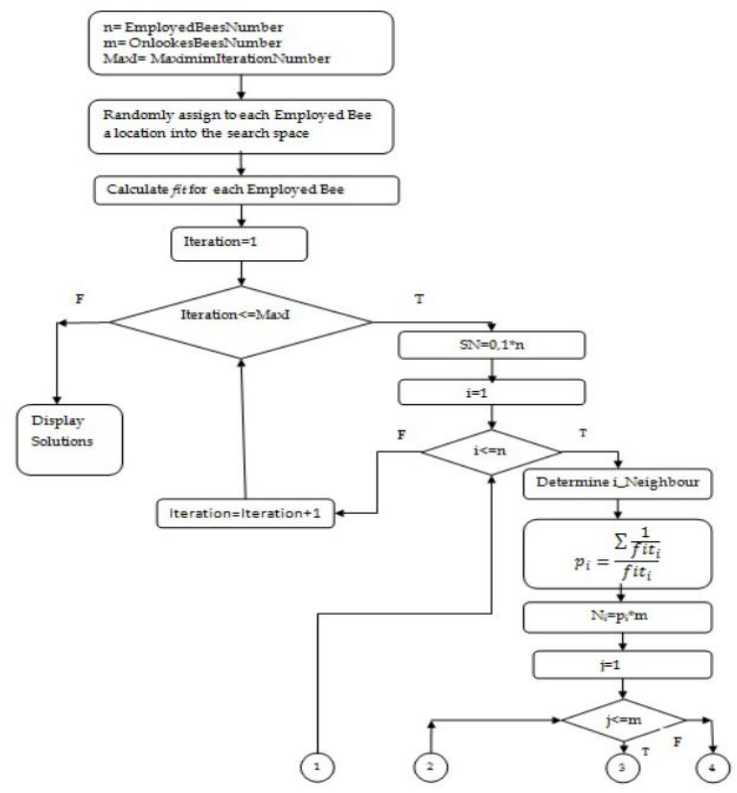

Figure 9: Artificial Bee Colony Schema [1]

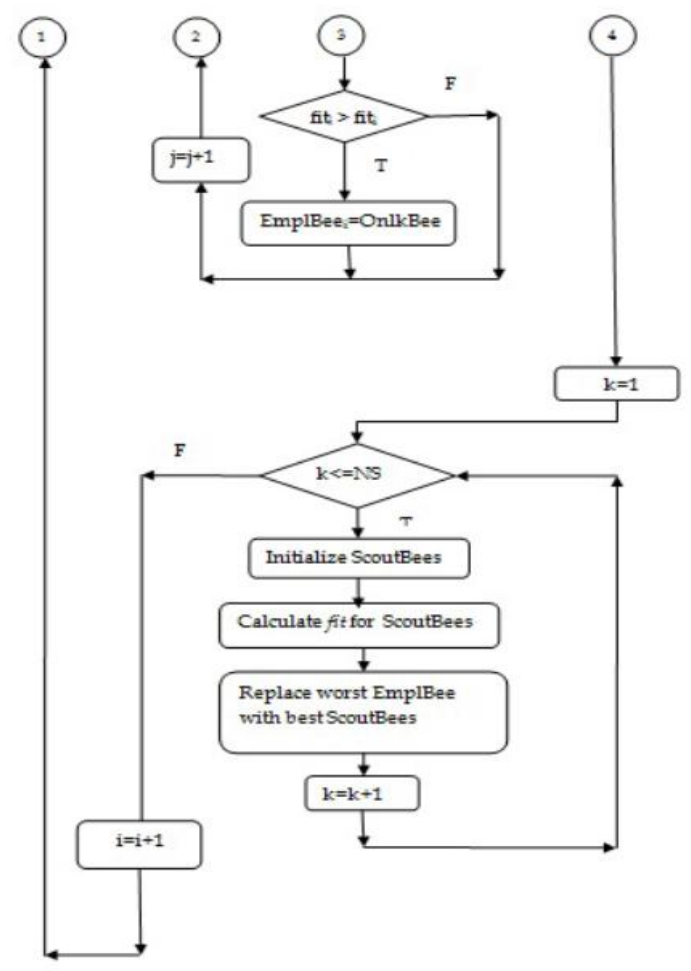

Figure 9: Artificial Bee Colony Schema (Contd.) [1]

Here the employed bees are assigned to a specific food location. They become scout when the amount of nectar on this area goes to zero. The out looker bees consider the waggle dance 
performed by the employed bees for food locations. Scouts navigate through search area without any assistance. A general assignment problem is represented by the necessity of assigning with a minimum cost set of tasks to a set of agents with limited capacity. Each task can be assigned to single agents and uses certain of this agent's resource. Here the proposed problem is based on set of learners $\left\{L_{l}, L_{2}, L 3 \ldots L_{n}\right\}$ attending a series of elearning courses. Based on the e-questionnaire's a learner's profile is associated to each candidate. There are set of Learning Units $\left\{L U_{1}, L U_{2 \ldots} L U k\right\}$ to be assigned to each student in order to maximize the student's performance. The search space here will be represented by learners. The bees will represent the $L U s$ and the constraints associated regarding simultaneously access of a specific $L U$ as at the one time student only can access a single Learning Unit, LU. After a learner has been assigned a LU a fitness function is calculated considering the learners' profile and the LU characteristics and the value of this fitness function needs to be maximized based on the parameters related to Mental Context(MC), Social Context(SC), Technological Context(TC), Knowledge Context(KC), Emotional Context(EC) and Class room Context $(C C)$. The fitness function of these parameters can be established from [1] with $\boldsymbol{E} \boldsymbol{q} .(2)$ as follows

$$
F_{i j}=\left(E-Q_{i j}+E_{i j}\right) / O_{j}
$$

$\boldsymbol{E}-\boldsymbol{Q}_{i j}$ here represents the value of knowledge the learner i has about the learning module $\mathrm{j}$ and $\boldsymbol{E}_{i j}$ defines the experience of the student for the area. $\boldsymbol{O}_{\boldsymbol{j}}$ refers to the occupancy degree of the considered learning unit.

\section{ii. Using Neural Network on adaptation of the pedagogical path for each learner}

To be able to implement the adaptability of the e-learning system and providing each learner proper teaching model. An instructor's model as explained by the author at [22] can be used. Here, the parents can be replaced by the guides/supervisors for monitoring performance of kids to be replaced as students can be mapped with the model explained in this section. The neural network can be trained with an input vector involving a certain output.

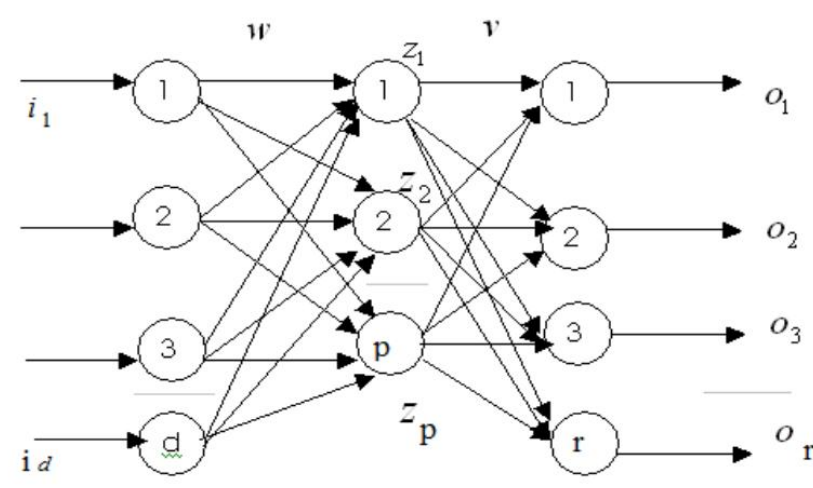

Figure 10: Schema using Neural Network for an Adaptive Teaching Model [1]

Here the input vectors are the parameters related to MC, SC, TC, $\mathrm{KC}, \mathrm{EC}$ as part of the instruction context. The neural network includes an input layer, a hidden layer and standard connection layers as can be referred in Figure 10. The input vectors form the part of input layer here. The output layer here correspond to the Teaching models based on the instruction context. The number of units from the hidden layer can be chosen using a heuristic method or one can adjust it during the folding of the teaching process in order to increase the complexity of the network. If we consider neural networks with $d$ inputs and $r$ outputs we can select $\sqrt{ } d *$ hidden units. The neural network has to resolve the association of an instruction context sacred to a learner with a teaching model obtained through the composition of the teaching models of each node from the conceptual map. Here the architecture does not change but the values of weights change. Often, the architecture of the neural network remains fixed and the values of weights change. In [8] it mentions that the positive weights determine the excitatory connections and the negative weights determine the inhibitory connections. The weights 0 denote the absence of connection between two neurons. The higher the absolute value of the weights is, the stronger the influence of the neuron $i$ on the neuron $j$ is stronger. The Instructional adaptive system has been developed here using the back propogation model in Figure 11 which will adjust the weights and train the neural network accordingly using concepts of supervised and unsupervised learning.

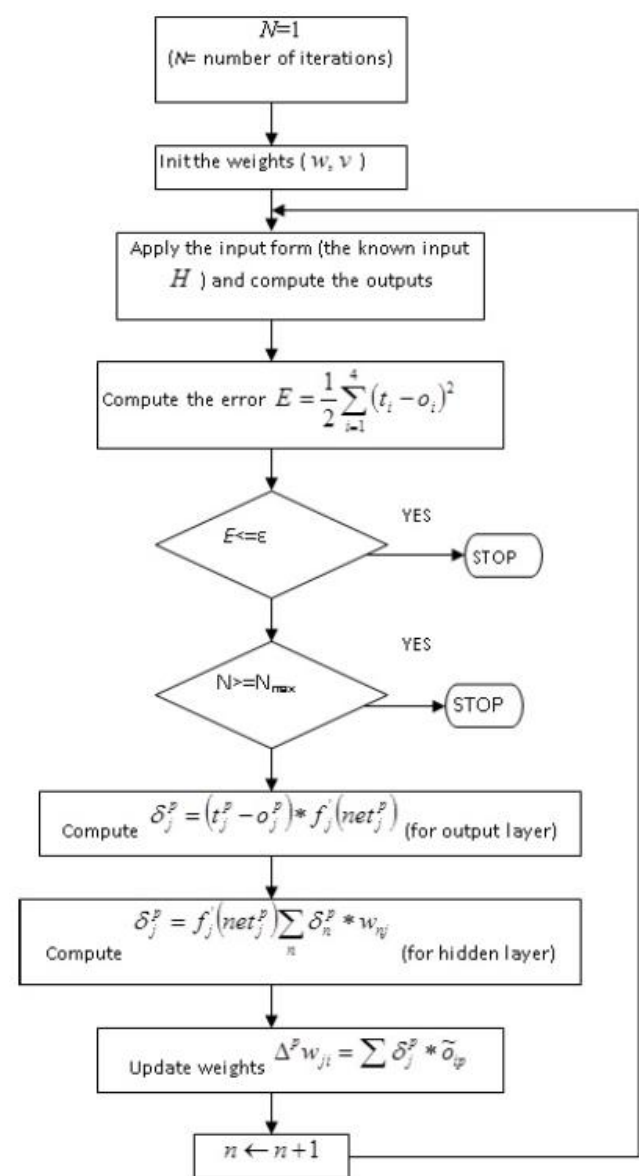

Figure 11: Backpropogation Model for the Adaptive Teaching Model

A hybrid based recommender system also has been deployed for learners at [17] has also been deployed using content based and collaborative filtering and reducing scalability issues using genetic algorithm at Figure 12 


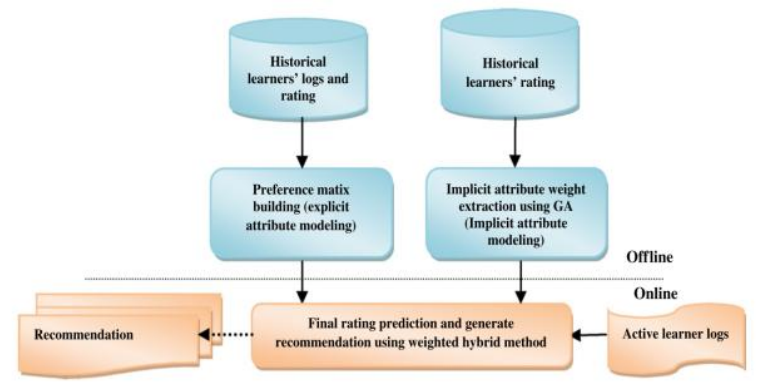

Figure 12: Framework for Recommender System using Genetic Algorithm [17]

\subsection{Developing Virtual or V-Labs}

In [8] to be able to develop capacity for Network Security education an innovative cloud based virtual lab has been proposed that utilizes open-source virtualization technologies such as Xen and KVM, and software defined networking solutions such as Open Flow switches to construct a scalable, reconfigurable and contained lab for network security education. This will be carried out with dedicated Virtual Machines (VMs) and Virtual Networks to students and a collaborative a collaborative laboratory environment with resource sharing and access control. A V-lab laboratory can consist of cluster of cloud servers with high performance capabilities and virtualization support as can be seen in Figure 13 for Single VM or Multi VM or Multi Network laboratories. A virtual lab is based on the principle of 3-phase pedagogical model which includes: learn basic knowledge; acquire and practice skills and abilities, collaborate and share knowledge. This model is extended with six factors Motivation, Knowledge, Creativity, Collaboration, Demonstration and Feedback.

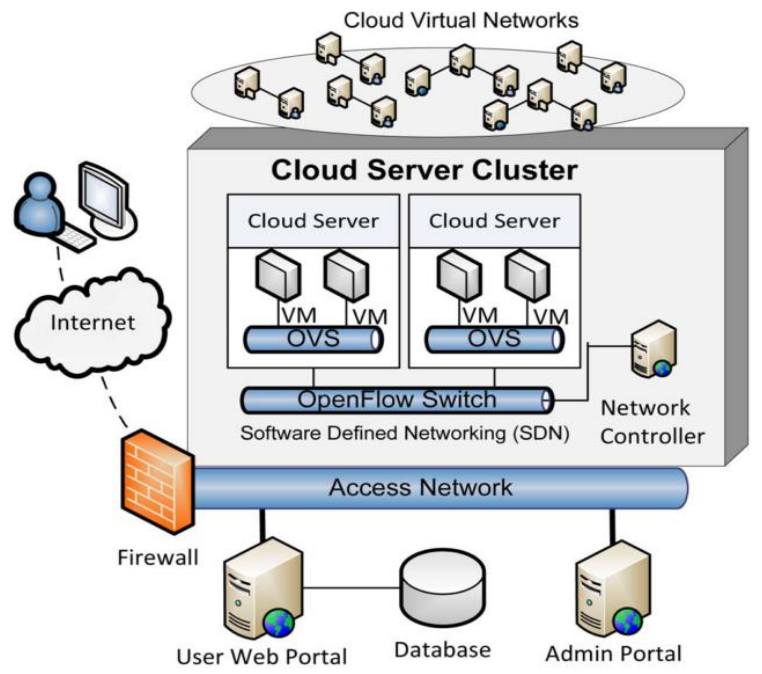

Figure 13: A Cloud Based Virtual Laboratory [8]

There is a huge scope to deploy gamification model and algorithms based on Bioinspired computing for virtual labs which will be discussed in detail in Section III and monitoring of student's performance mapping to the Parent -kid model explained at [22] for monitoring performance of students carrying out their higher education studies. Countries like USA, India, Canada and Japan are already deploying virtual labs across various niche institutes of higher technical education to give remote access to students for their various experiments for Energy solutions, Computer Applications and Networking and Smart Cities. These models can be referred to be able to develop joint collaborative programs for enhancing practical skill based on the second phase of the pedagogical model for the Virtual laboratory as derived by the authors of this section.

\subsection{Markov Model based Classrooms}

Distribution of teaching material based on the standard formats like SCORM, IMS, LOM, AICC proposed by the international organizations have made it possible to share, reuse and recombine teaching materials in different Learning Management Systems. As seen from the previous sections cloud computing resources can be best used for distribution of these E-learning resources and materials to various target users as instructors, domain experts and learners. In [15] a Markov Model based prediction method is proposed to understand the learners' requirements and accordingly provide the E-learning contents on a cloud platform (Refer Figure 14) as follows:

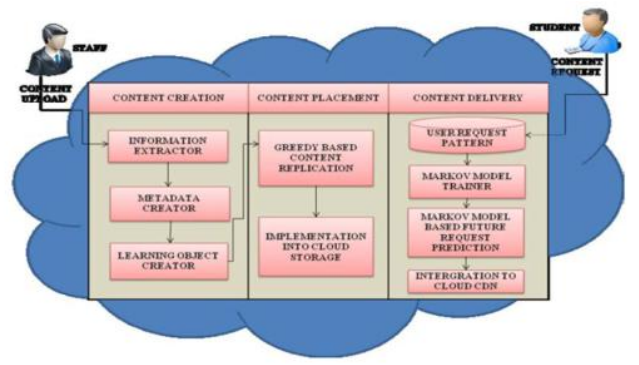

Figure 14: Markov Model based Prediction Method for Elearning on cloud computing [15]

Here, load balance is created for storing the learning object using the content distribution networks using greedy based approach for minimizing the cost of storage, access of e-contents by the students. A training data is created based on collection of requests of students. The training data undergoes transition from one state to the other, among countable number of possible states. The Markov Model with its transition between various states are used for calculating the transition probabilities between various states which are the student requests for the learning object. Based on the transition probability matrix and the current request of the learner, the future request based on the Markov chain will be obtained and replicated to the user's site reducing the access time whether the predicted content is present or not. Further, in [16] for web based interaction for delivering the resources related to e-learning is based on a 3-phase model which includes determining the learning style using the VAK model (which is Visual, Auditory and Kinesthetic learning), use the Kcluster algorithm for identifying the learning style and initializing the Hidden Markov Model for the content delivery using the content delivery network (CDN) to create an effective adaptive learning system and has been deployed using the following steps:

- The details of the learners, courses taken, etc. are stored in the following matrix as $S=\left[\begin{array}{lll}s_{l} s_{2}, s_{3}, s_{n}\end{array}\right]^{T}$. There are ' $\mathrm{N}$ ' learners to whom ' $\mathrm{M}$ ' questionnaires related to VAK model will be asked.

- A $N x 3$ matrix is generated as a 3-tuple training set for the cluster as

$$
S_{i j}=\left[\begin{array}{l}
S_{11}, S_{12,} S_{13} \\
S_{21}, S_{22} S_{13} \\
S_{31}, S_{32}, S_{33}
\end{array}\right]
$$


Where, each row corresponds to a feature vector of one learner consisting of three elements, each epresenting a learning style from the VAK model on which the learners will be clustered. This is based on K-means cluster algorithm mentioned at [16] Here, $S_{i j}$ are number of questions the learners or students $i$ answered in favour of the learning style $j$. To classify into distinct classes the data the cluster location is specified. Here, the learner will be associated with a cluster that is minimum distance to its score w.r.t centroid of the cluster. In [16] this is specified based on the following equation:

$$
\begin{aligned}
& D_{i j}=\left[\begin{array}{lll}
d_{11} & d_{12} & d_{13} \\
d_{21} & d_{22} & d_{23} \\
d_{n 1} & d_{n 2} & d_{n 3}
\end{array}\right]
\end{aligned}
$$

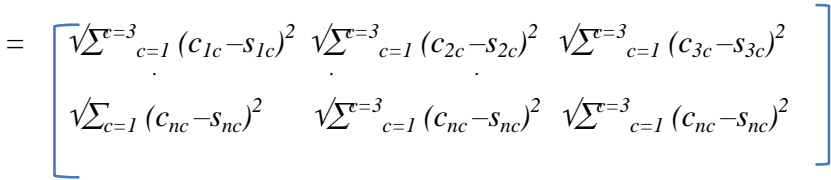

Here, $D_{i j}$ is the minimal distance between the learner $i$ from the centroid of the cluster. Multiple iterations of the algorithm is computed where after assigning cluster for each student a new centroid for each cluster is calculated. The centroid for cluster $j$ is accordingly computed as the mean average value of each student from cluster $j$. Till the centroids for all clusters remain in the same place this step will be repeated till the value remains unchangeable.

- Further, in [16] performance has been determined for the learners for the content delivery using the following parameters of the Hidden Markov Model(HMM) which includes Transitional Probabilities(A), Observation Probabilities $(B)$ and Initial Probability Distribution $(\pi)$ to defining the conditional probabilities of a given current state based on observations estimated along with the probability of a previous state. The VAK model here is part of the hidden state and the transition from one hidden state to the other is captured in the State Transition Matrix. In Markov process is of the order one and will depend on one preceding state. And is represented as follows:

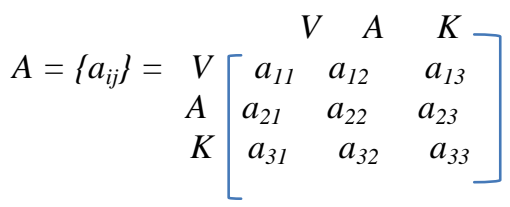

The transition matrix here determines the probability in which learner changes his/learning style and here the matrix A has stochastic row where each element is a probability and the sum of all elements in the row is 1 . Here, $a_{23}$ has changed its learning style from auditory at time $\mathrm{t}$ to kinesthetic at time $\mathrm{t}+1$ and $\mathrm{a}_{21}+\mathrm{a}_{22}+\mathrm{a}_{23}=1$ and can be represented as:

$$
a_{i j}=P\left(\text { state } q_{l} \text { at time }(t+1) \mid \text { state } q_{i} \text { at time } t\right)
$$

The initial distribution $\pi$ is determined from the clustering data using K-means algorithm. The observation probability matrix defined here is:

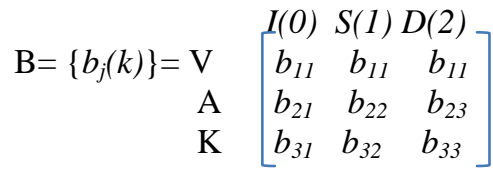

Where $I(0)$ is the improved performance, $S(1)$ is static performance and $\mathrm{D}(2)$ is deteriorated performance. The observation matrix here is row stochastic and independent of time t.

- A Training model can be deployed with Hidden Markov Model for intelligent content delivery by computing matrices $\mathrm{A}$ and $\mathrm{B}$ as mentioned here based on the length of observation sequence $\mathrm{O}$ with $\mathrm{I}(0), \mathrm{S}(1)$ and $\mathrm{D}(2)$ performance mentioned here of an initial learner test group which can be limited. The learning algorithm for the model $\lambda=(\mathrm{A}, \mathrm{B}, \pi)$ is determined by forward and backward algorithm with time $\mathrm{t}$ and $\mathrm{t}+1$ respectively using recursive computations and probability of observations are calculated for each $\lambda$. The content will then be delivered to the student according to these probabilities.

An architecture for determining the learning needs has also been used for the result and analysis in [16] at Figure 15 as follows:

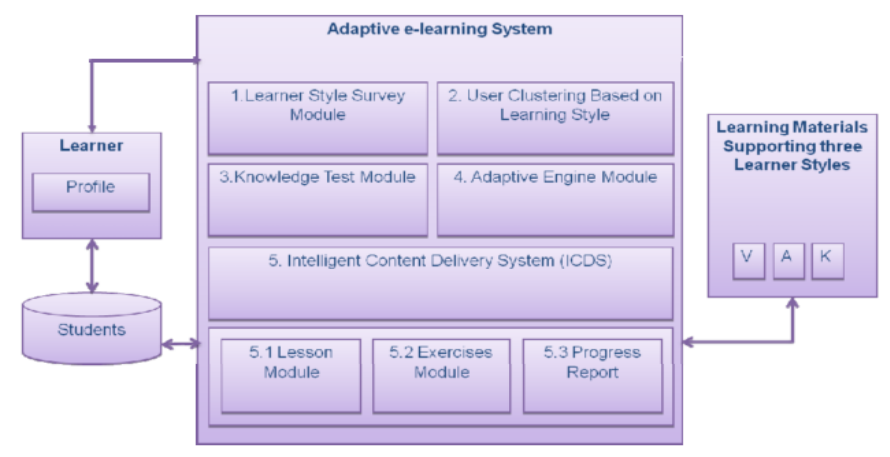

Figure 15: Adaptive E-learning using HMM process for Intelligent Content Delivery [16]

The K-means algorithm currently deployed to model learners/students in the VAK model can also be replaced and deployed using the fitness function from the evolutionary algorithm for optimized intelligent content delivery under the markov process chain during scalability issues during specific learning requirements with dynamic observation sequences.

\section{DEVELOPING COLLABORATIVE MODELS FOR JOINT ACADEMIC PROGRAMS FOR RESEARCH \& INNOVATION}

In the Saudi Arabia Vision 2030 one of the strategic goals of the Ministry of Education (MOE) is to improve the learning environment to stimulate creativity and innovation. To be able to move towards becoming knowledge economy based on World Bank Knowledge Based Economic (KBE) framework (Refer Figure 16): 


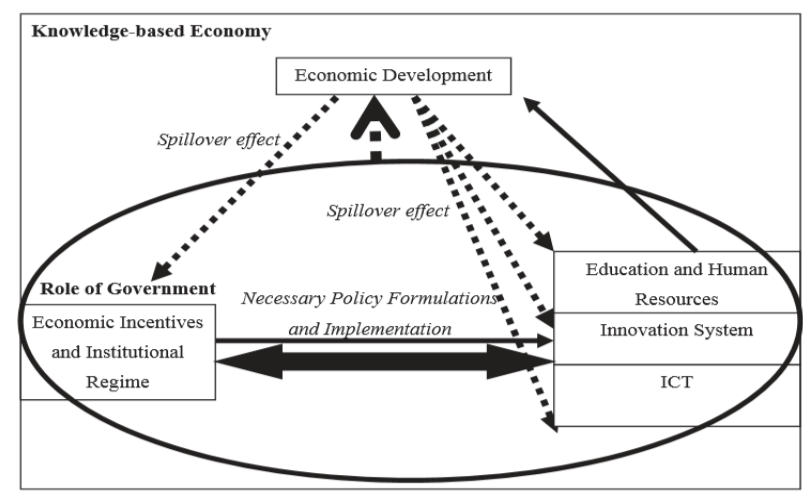

Figure 16: Knowledge Based Economy Framework [18]

The globalization process in education sector plays a significant role towards building a workforce that can value add towards meeting the demands for the sectors that play key role in the growth of any nation as mentioned in [6]. Further, the globalization in higher education has enabled integration of higher education systems between the countries. The Bologna process for the "European Higher Education area", Policy cooperation between Caribbean countries and South America and the African Higher Education Area (AHEA) has been successfully created to be able to establish their own higher education areas. The new teaching learning methods using ICT infrastructure or technology enhances towards internationalization of education and enable building an effective 'higher education area' based on collaboration between countries for the same. E-learning helps in establishing synchronous and asynchronous mode of learning creating a dynamic environment for new pedagogy methods. This has been developed further with the emergence of Massive open online course (MOOC) models for effective learning in higher education and is being used by the 'net generation learners'. The few examples here are USA(coursera, edX, Udacity), Australia(Open2study),Brazil(Unopar), China(Xuetang), Germany(iversity), Japan (JMOOC), India (Swayam) and Malaysian and New Zealand universities are using several MOOC models for higher education. It has been found that MOOC make learning more engaging, play a crucial role as teaching laboratories (please refer with the various virtual class room models from the previous sections), add value to courses in University campuses, ehances skill for career development with open access to education with the culture and economic diversity. MOOCs typically use cloud computing and are often created with authoring systems. Authoring tools for the creation of MOOCs are specialized packages of educational software like Elicitus, IMC Content Studio and Lectora that are easy-to-use and support e-learning standards like SCORM and AICC. Further, it is also imperative to develop an Inter University collaborative model on ICT infrastructure for knowledge sharing, creating pedagogy tasks based on the expertise with the faculties a highly dynamic learning environment in a cross campus dynamic learning environment where demography is not a constraint. In KSA, as described in [18] $R \& D$ collaboration between business communities and local universities will bring meaningful results towards technology innovation and patent and patent citations provide strong indication of innovation output for its economy. Internationalization of Higher technical education under various policy framework of Ministry of Education (MOE) can be achieved through Inter University collaborations for academia and research can also contribute towards building the innovative ecosystem as envisioned in [7] for key research areas which includes: Water, Energy, Advanced materials science and technology, Biotechnology, Building and construction. This section specifies the different collaborative models with developed countries and countries with emerging economies that can be considered using the ICT infrastructure for adaptive elearning to stimulate research and innovation in the higher education for building up a knowledge based economy that can create opportunities for not only the local citizens but also serving the needs of GCC and other developing countries thus making Saudi Arabia a hub for not only middle east but other global economies for research and innovation in the area of Higher Technical Education. The previous section demonstrated various state of the art virtual classroom using Bioinspired algorithm and virtual lab models using cloud computing. In this section we will try to develop a collaborative model related to joint academic and research activities using the Deep Belief Network platform developed here for interuniversity exchange related to the Teaching-learning process.

\subsection{Need for a Collaborative Setup for Joint Academic Programs for Research and Innovation}

In the recent past as mentioned in [19] the Saudi Government has built in active relationships with overseas universities and have supported its students pursuing their higher studies in Europe, USA, UK , Canada and UAE and have also explored opportunities related to multiple collaborations in higher education of the Saudi Arabia Universities with Asian countries which includes China, India, Malaysia, Japan, Singapore and South Korea under the 'look east strategy' for tertiary level studies in medicine, science and engineering. The objective has been to create an employable workforce towards the development of the science and technology sector for the economic growth of the country. However, for the cost effective spending towards higher education by the government and a need to create human capital for development in the niche areas identified by the Saudi Arabia Government the capacity of the current setup of the universities will need an upgradation and more opportunities for enhancement in higher education such as doctoral programs will be required with these universities. With strategic trade interdependency and agreements with various countries a joint academic program can be developed to support research and innovation in the Saudi Arabian Universities that can help reduce spending by the government to send students for higher education overseas. An employable workforce as part of the knowledge economy can be generated with facilities created for higher technical education in the current local universities itself. An adaptive e-learning mechanism to support the higher education can be developed to support collaborations for research and innovation for the growth and development of the sectors as mentioned above and currently envisaged under the vision 2030 by the Ministry of Education (MOE) towards building its knowledge economy under the globalization process. The collaboration model will need to be adapted from [20] to be able to create process towards creating virtual classrooms in a cross campus environment to enhance cooperation in joint academic programs for research and innovation as proposed by the author of this paper as follows: 
Creating a Virtual University with collaboration based on common Research Goals

\begin{tabular}{|c|c|c|}
\hline \multicolumn{2}{|c|}{$\begin{array}{l}\text { Formation of Joint Research Groups and Creating Virtual Labs with } \\
\text { appropriate access to facilities available with Universities(decentralised) }\end{array}$} & $\begin{array}{l}\text { Setting up Course Materials and } \\
\text { Virtual Classrooms }\end{array}$ \\
\hline $\begin{array}{l}\text { Creating an Academic Leadership body } \\
\text { working towards Institutional goals, } \\
\text { departmentalldivision goals and Individual } \\
\text { goals for faculties, staff and students }\end{array}$ & 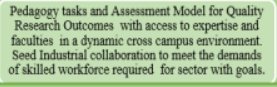 & $\begin{array}{l}\text { Enhance learning goals for students locally in } \mathrm{Si} \\
\text { Arabia and making a global hub for higher } \\
\text { education, neeating workforce wuth skills that } \\
\text { them employable at a global level }\end{array}$ \\
\hline
\end{tabular}

Figure 17: A Proposed Adaptive E-learning InterUniversity Collaboration framework for Higher Education in KSA

The use of cloud computing with the deployment of content delivery networks using Bioinspired algorithm or evolutionary concepts (Refer Section II) will be required to integrate and optimize an existing learning management systems (LMS) for the virtual classrooms to be able to develop Joint Adaptive Elearning mechanism for Higher education. The benefit of developing such model will enable international universities and KSA universities to create library of content materials for easy access to students at different demographic location as a part of this collaboration to be more productive in terms of producing more joint research papers for S\&T publications and improve KSA's S\&T Research publication index, come up with joint patents creating Intellectual Property Rights as an advantage to both KSA and other countries in the university partnership. More academic opportunities in the Teaching-learning process where instructors and students will have access to each other anywhere and anytime creating a multi instructional environment for student learning at a global level. It will be imperative to develop learning goals for the students and learners for competency required based on the current needs of the Industrial sector (Refer Figure 18)

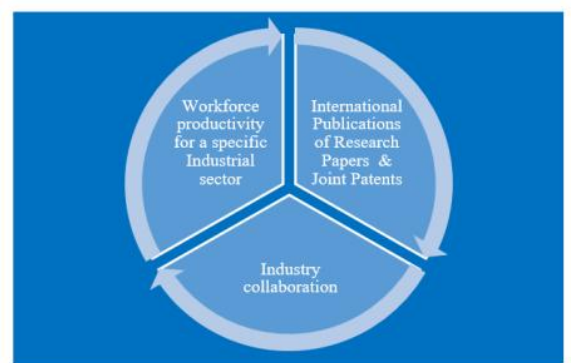

Figure 18: Learning Goals for an Adaptive E-learning setup

A seed funding can be created for such an institutional mechanism by establishing an Adaptive e-learning based Virtual University institutional mechanism as proposed in Figure 17 under the various policy framework under the Ministry of Education (MOE) to create human capital from these virtual universities for creating workforce at a global level for the sectors identified to make Saudi Arabia a destination hub for GCC and other developing countries in the Higher Technical Education sector. The model can also be used to create a consortium of universities for developing human capital for research and innovation in Biotechnology, Water, Engineering, Agriculture, Science and healthcare.

Creating such Adaptive E-learning models will have their own inherent issues in deployment of an Inter University partnerships on virtual clouds and networks will need more training to changing dynamics of a learner's environment. The key here will be to develop pedagogy tasks based on dynamic activities carried out in a virtual class room or lab environment by the students to be managed by the Instructors module in presence or absence of the Instructor or the faculty. While, the HMM prediction method suggested in the previous section helps in determining the category of learner's style for content delivery and can be deployed on an existing content delivery network for providing the learner's unit from the pedagogy module. Deploying greedy algorithm using the Dijkstra's shortest path method can be further deployed for giving access to the student/learner based on the performance matrix as generated by the HMM prediction method of the previous section. However, greedy algorithm using Dijkstra's method have certain disadvantage it does a blind search there by consuming a lot of time waste of necessary resources. Another disadvantage is that it cannot handle negative edges for an unsupervised learner's category identified with the HMM prediction method. This leads to acyclic graphs and most often cannot obtain the right shortest path. Further, in the HMM model the hidden states do not have any dependencies and it may be imperative to have different combined categories in the VAK model like VA, AK and VK which will needed to be further handled and trained to the HMM Prediction method explained in the previous section. While evolutionary algorithm concepts using Neural Networks for an adaptive e-learning setup can be best trained using Backpropogation algorithm as specified in the previous section above. However, a neural network with many hidden layers cannot be easily trained through backpropagation alone, due to the vanishing gradient problem caused by an activation function 'sigmoid' or 'tanh' as mentioned in [1] for creating association between the learner and the learner units accordingly. Further, each unit sees only its inputs and the error signal propagated back to it from the network's outputs. The error signal defines the problem that the unit is trying to solve, but this problem changes constantly. Instead of a situation in which each unit moves quickly and directly to assume some useful role, we see a complex implementation among all the units that takes a long time to settle down. Keeping in view, the next section proposes a learning-teaching process model using the deep belief network using differential evolution algorithm for training the network towards adaptive learning which will be discussed in the next section.

\subsection{Developing a Collaborative Deep Belief Network Platform for Virtual Classrooms and Labs}

To be able to create a collaborative environment for an adaptive teaching learning process in this section we will try to extend our scenario based on user specific needs for multi instructional environment based on task environment as already illustrated by the author of this paper in [22] where the parentkid model can be mapped with the Supervisor, Co- Supervisor and student carrying out his doctoral Programme in a virtual class room setup as proposed by the author in Figure 17. A collaborative vitual lab and classroom environment will be also built up by training the Deep Belief Network Platform in an interuniversity virtual setup as proposed by the author. In this section we will consider scenarios of developing two types of virtual labs: simulated and remote controlled from [23] for synchronous (group of people attending an interactive session) and asynchronous (self-paced and user specific) mode of learning. A typical simulated lab environment and remote controlled lab setup can be deployed on a Content Delivery Network platform (Netflix, BBC are already using such a setup as the platform) using the Software Defined Network (SDN) 
based Open Flow Switches for the Deep Belief Network set up as illustrated in Figure 19 below :

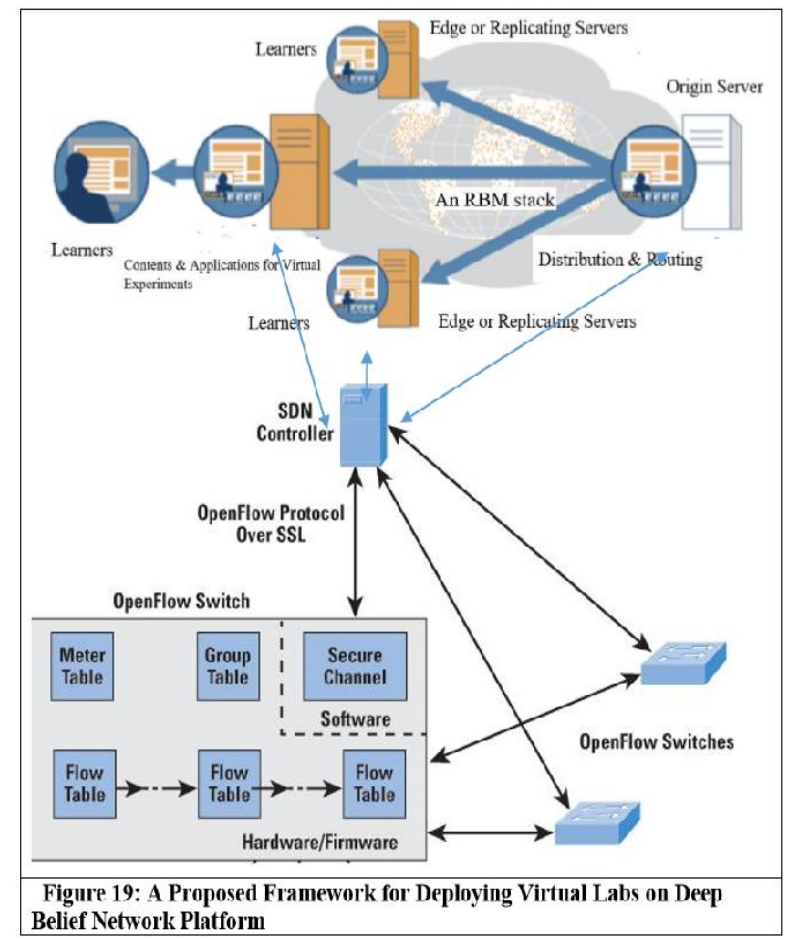

In the figure above for the deep belief network platform the Restricted Boltzmann Machine (RBM) stack machines are deployed separately on the Edge, Replicated or Surrogate servers for its immediate users or learners, accordingly RBM stacks are deployed on the distribution server as well as the original server of the content delivery network used in Figure 19 above. The RBM stack at different hierarchial setup of a Content delivery network can be adapted for Virtual lab experiments with typical scenario of Bioinspired robotic remote access lab from [23]. A content delivery network for an adaptive virtual lab and virtual class room environment typically can include a knowledge domain server with joint experiments and a lab catalog for carrying out student experiments where schedules are determined for each lab experiment to determine the learner's ability. This knowledge domain server is the content provider for a typical interuniversity setup across campus for the lab experiments under the various joint research programs and based on number of user sessions it receives for remote experiments. To be able to avoid the load on the knowledge domain servers the contents are replicated on the surrogate or edge servers located nearest to the users, here the user sessions are not always required to be reinitialized and can typically cater to the experimental needs based on learner's ability for specific experiments related to a Bioinspired robotic remote access lab at [23]. The experiments can be determined with various stages of learnings and outputs by defining the schedules of each experiments based on their complexity. The RBM stacks can be deployed on these surrogate servers for each layer in a Deep Belief Network platform. A typical Deep Belief Network is best explained in the Figure 20 as follows mapping to the deployment needs of Figure 19:

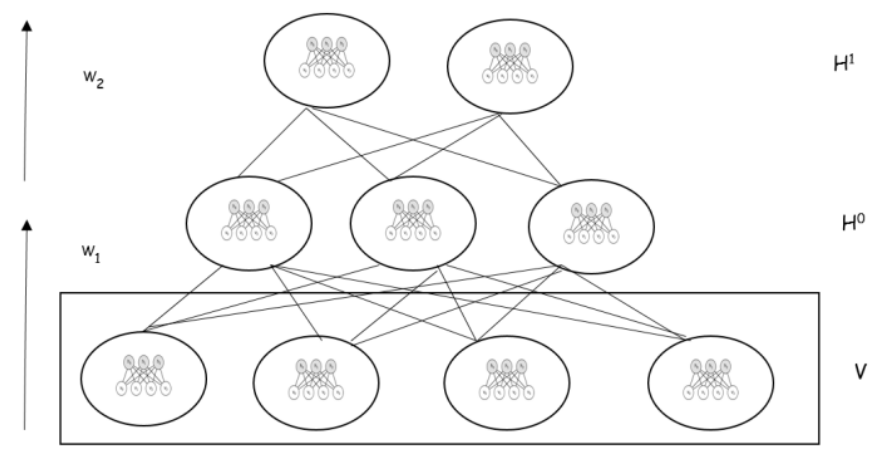

Figure 20: A Multilayered Cascaded RBM Machine for forming the Deep Belief Network Platform

Here each of the 2-layered Restricted Boltzmann Machine $(\mathrm{RBM})$ on the replicated or edge server of the content delivery network with its own visible and hidden layer classified as learning units, LU will be part of the visible and hidden layer to form a multi layered cascaded RBM machine for a deep platform network. Here the weights associated between the different visible and hidden units determines the need to associate different categories of learners or a combination of different categories of learners for a specific mapping to a learning unit as explained with the limitation in Hidden Markov Model for adaptive learning in the previous section. This will be given as feature vector inputs in the visible layer of the multi layered cascaded RBM machine forming the Deep Belief Network Platform as proposed by the author of this paper. The basic need of developing a distributed RBM stack layer for a Deep Belief Network platform for virtual labs and class rooms is used to reduce computational complexity and such solutions can also be deployed with existing hardware infrastructure for the adaptive learning management systems. Further, to this for defining pedagogy tasks with different instruction levels different categories of learner's profile can also be defined based on the performance parameters with synchronous and asynchronous learning mode for carrying out different experiments for research that can also serve as feature vector inputs of the learner's profile. The need for using deep belief network will be for meeting the teaching and learning environment needs in a virtual setup mentioned in Figure 17 and 18. While in [24] for training the network the contrastive divergence method using the K-steps Gibbs sampling method has been used. However, during the weight initialization in the proposed distributed multilayered cascaded RBM architecture for the deep belief network platform while initializing the weights latency can be observed while establishing association between the visible and hidden units. The correlation between the $\left\langle V_{n}, H_{n}\right\rangle$ the visible and hidden units can also be determined during the unsupervised and supervised training of the network using the poisson point process model based on the different categories of learner's profile as the network becomes experienced in handling the pedagogy tasks during the teaching and learning process as specified in Eq. 6 below:

$$
P(V / H)=e^{-u} \kappa^{j} / j !
$$

Here, the probability distribution is for correlation of the visible units with hidden layer and its success occurrence determined bу $\kappa$ where $j=1,2,3,4 \ldots, n$. This is defined during the weight initialization of the deep belief network platform. We assume all the individual RBM machines in each of the visible and hidden 
layers in Figure 20 are already initialized from the Algorithm 1 and 2 in [25]. Based on Equation 6 the correlation between the visible and hidden units can be further determined for the proposed architecture in Figure 20 using the Differential Evolution , DE Algorithm as follows for the user specific learning is proposed as follows :

Proposed Algorithm: Training DBN for Virtual Lab and Classrooms

Intialise $V, H$
For $W$ for each $V, H$
Determine $P(V / H)$ from Eq. 6

For every mutation as fitness function for $\mathrm{H}$ unit repeat following steps:

Pick a category L from the Learner's Profile Unit where L $\in\{1,2, \ldots n\}$ (as the solution and problem to be optimized based on the dimension specified)

Compute the new position of the $V$ unit as follows by determining the crossover probability using Eq.6

Determine $W$ based on different parameters of fitness function of Deep belief network determined by latency, learning rate, epochs, etc.

From the population of $V$ units with the highest fitness and lowest cost is the best candidate solution for correlating $\langle V, H\rangle$ in DBN platform.

It can be observed here that for a multi-dimensional valued function differential evolution does not need to use a differential problem unlike gradient-descent problem while training a neural network. And can serve as a self-learning optimization algorithm for fine tuning of the Deep Belief Network based on the learning style of students for different remote or simulated lab experiment scenarios in a joint research program in a collaborative virtual setup. Further, the solution can also be deployed without using greedy algorithm for layer to layer training as defined in [24]. The proposed architecture will be able to meet the needs of improving the quality of research and employable work force with marketable skill sets implementing this setup in Figure 20 in a dynamic e-learning environment and can stimulate an ecosystem for value adding towards research and development mapping to the parents kid model in [22] specified by the author to Teacher student learning environment towards Higher education. It will be imperative to deploy existing deep learning tools with existing learning management system and enhance for the proposed model in this section by the author.

\section{CONCLUSIONS}

In this paper, we have understood the need to create an adaptive e-learning environment using various proposed bio inspired and evolutionary algorithm for setting up an effective teaching learning process model in higher technical education using the parent-kid model in [22] mapped to supervisor/guide with students from higher technical education stream. In the future scope of work for deploying deep belief network architecture in a Multi-layer cascaded RBM machine this algorithm where mapping of hidden and visible units will not be layer by layer but independent of each layers. Architectures of Deep Belief Network with various other Deep learning methods like RNN, CNN will also be explored. The models proposed by the author in Section III of this paper can help in creating investments in the Higher education sector making Saudi Arabia a hub for global education hub by not only creating employable workforce locally but also serving the education needs of other nations in the area of Higher Technical Education through interuniversity collaborations. Thus, increasing the market share of Technology vendors in this sector. Also, as currently extensive research is being carried out to optimize the memory architecture for a deep learning network it is possible to deploy differential evolution algorithm on a deep belief platform for collaborative environment between universities at different demographic locations of an Internet of Things enabled smart campus. This can also be a cost effective solution for deploying it in the existing ICT setup in the country thus meeting to the needs of creating an employable workforce in the niche areas as envisioned by the Ministry of Education, MoE of Saudi Arabia. Further, in the future work the author will also try to analyse the impact of IoT enabled virtual class room (Refer Figure 21) from [21] on the existing virtual institutional mechanisms proposed in Figure 17 based on Inter University collaborations. Also smart learning devices will be built up deploying deep learning concepts based on Fractal MIMO solutions as a part of compact antenna design for these devices will be proposed for such high end interactive learning solutions in a Smart Campus environment.

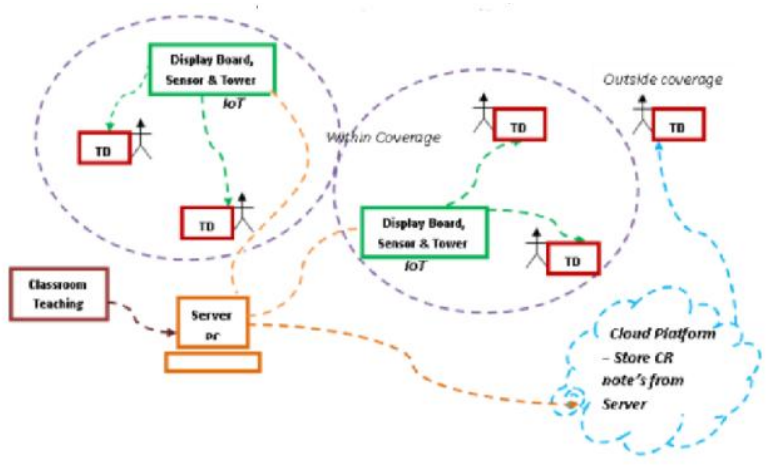

Figure 21: Class room note sharing in an IoT enabled smart E-learning campus [21]

Collaborative and cooperative learning and pedagogy tasks will be the need of the future as higher technical education evolves in Saudi Arabia for development of its key sectors in healthcare, industrial development, science \& technology towards the Ministry of Education's 2030 vision.

\section{REFERENCES}

[1] [1]Moise, G., Gabriela, M., Loredana, N., \& Alina, T. F. (2017). Bio-Inspired E-Learning Systems A Simulation Case: English Language Teaching A Simulation Case: English Language Teaching, (April). https://doi.org/10.5772/31268

[2] Al-asmari, A. M., \& Khan, M. S. R. (2014). E-learning in Saudi Arabia: Past, present and future.

[3] Bose, S. (n.d.). I t s \& e u e f, 1-26.

[4] Pratt, J., Hoult, E., Nairne, B., \& Ashenden, S. (2011).Collaboration Between Universities.

[5] Adaptive learning. (n.d.).

[6] Delhi, N. (2016). Report on the N. V Varghese Sayantan Mandal Report on the N. V Varghese Sayantan Mandal.

[7] Britton, K., \& Officer, P. (2016). Date: I-Note Number: Contact :, (June). 
[8] Xu, L., Huang, D., \& Tsai, W. (2014). Cloud Based Virtual Laboratory for Network, 57(3), 145-150.

[9] Oladimeji, I. W., Technology, A. I., \& Polytechnic, O. S. (2016). International Journal of Science and Applied Information Technology Design of Cloud based E-learning System for Virtual Classroom, 5(1), 1-6.

[10] Ferreira, E., Ferreira, D., Kim, S., Siirtola, P.,Röning, J., Forlizzi, J. F., \& Dey, A. K. (n.d.). Assessing real-time cognitive load based on psycho- physiological measures for younger and older adults.

[11] https://elearningindustry.com

[12] http://tincanapi.com/scorm-vs-the-tin-can-api/

[13] Technologies, N. (2015). A Hybrid Bioinspired Algorithm for Facial Emotion Recognition Using CSO-GA-PSOSVM,472-477https://doi.org/10.1109/CSNT.2015.124

[14] Joseph D. Novak \& Alberto J. Cañas (2006). "The Theory Underlying Concept Maps and How To Construct and Use Them", Institute for Human and Machine Cognition. Accessed 24 Nov 2008.

[15] G. Malini, T. Mala., \& A. Kannan.(2016),Asian Journal of Information Technology 15(17):3280-3286. Markov Model Based Prediction for Effective E-content delivery in Cloud.

[16] Deeb, B. (2014). An Adaptive HMM Based Approach for Improving E-Learning Methods.

[17] Salehi, M. (2013). Hybrid attribute-based recommender system for learning material using genetic algorithm and a multidimensional information model. Egyptian Informatics Journal, 14(1), https://doi.org/10.1016/j.eij.2012.12.001
[18] Chandra, S. (n.d.). Creating the Knowledge based Economy in Kingdom of Saudi Arabia to Solve the Current Unemployment Crisis.

[19] The Observatory on borderless Higher Education (2006), (March), 1-4

[20] INTERNATIONAL COLLABORATION IN HIGHER EDUCATION: THE CANADIAN-UKRAINIAN CURRICULUM DEVELOPMENT PARTNERSHIP by Valentyna Kushnarenko A thesis submitted in conformity with the requirements for the degree of Doctor of Philosophy Department of Theory and Policy Studies in Education Ontario Institute for Studies in Education University of Toronto (C) Copyright by Valentyna Kushnarenko (2010) INTERNATIONAL COLLABORATION IN HIGHER EDUCATION: THE CANADIAN-UKRAINIAN CURRICULUM DEVELOPMENT PARTNERSHIP . Department of Theory and Policy Studies in Education University of Toronto. (2010).

[21] Mohanapriya, M. (2016). IOT enabled Future Smart Campus with effective E-Learning : i-Campus, 3(4), 81-87. https://doi.org/10.5176/2251-3701

[22] Fakeeh, K. A. (2016). KSA 2030 Vision (Kingdom of Saudi Arabia's 2030 Project) and its Focus on Families and Students, 149(1), 46-48.

[23] Achuthan, K., Nedungadi, P., Raman, R., \& Nair, B. (n.d.). Complementing Education via Virtual Labs : Implementation and Deployment of Remote Laboratories and Usage Analysis in South Indian Villages, 8-15.

[24] Hinton, G. E., \& Osindero, S. (2006). A fast learning algorithm for deep belief nets *

[25] Kim, J. W. (n.d.). Classification with Deep Belief Networks. 